\title{
How Students Fail to Self-regulate Their Online Learning Experience
}

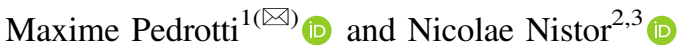 \\ ${ }^{1}$ Leibniz Supercomputing Centre of the Bavarian Academy of Sciences and \\ Humanities, Garching n. Munich, Germany \\ maxime.pedrotti@lrz.de \\ ${ }^{2}$ Faculty of Psychology and Educational Sciences, Ludwig-Maximilians- \\ Universität München, Munich, Germany \\ ${ }^{3}$ Richard W. Riley College of Education and Leadership, Walden University, \\ Minneapolis, MN, USA
}

\begin{abstract}
Given the rising popularity of online-based learning scenarios such as MOOCs, flipped classrooms and regular lecture recordings, students face new challenges compared to traditional classroom settings. This paper explores the role of self-regulated learning (SRL) strategies in online learning environments specifically when working with online lecture recordings - and how university students apply SRL strategies to reach their learning goals. To this end, a series of thirteen problem-centered interviews was conducted with undergraduate students of the learning sciences at a major German university. The findings reveal a dramatically suboptimal use of SRL strategies, leading us to the conclusion that interventions such as basic time management and general planning strategy training may have to be implemented more firmly in undergraduate education, in order to enhance university students' future learning experience.
\end{abstract}

Keywords: Learning strategies - Self-regulated learning - Online learning • Problem-centered interviews $\cdot$ Higher education

\section{Introduction}

Given the rising popularity of online-based learning scenarios such as MOOCs, flipped classrooms and regular lecture recordings, students face new challenges compared to traditional classroom settings. While higher education in general is marked by a higher level of self-regulation - most lectures do not require or register attendance by students, online-based classroom settings take this to a whole new level.

Traditional face-to-face classes have fixed, mostly regularly recurring session times, during which attendance is required at least for learners to be able to receive the contents taught in class. In blended or purely online-based learning scenarios, however, learning materials are usually placed somewhere accessible online, ready to be used on demand with limited time constraints (the only fixed dates being final or intermediate exams or exercise returns). The "when" and "where" of students" accessing and working on the contents is left up to the students themselves, which significantly raises 
the level of self-regulation required to successfully reach the learning goals set by instructors (and students, albeit to themselves) for the respective course program [1].

As recent research has shown [2], learning strategies can have positive impact on students' academic achievement, however, there are individual differences, and some strategies (e.g. help-seeking, elaboration) may rely on the learner's prior knowledge and experience, as well as their prior application of strategies known to them. This paper explores the role of self-regulation learning (SRL) strategies [3] employed by students in higher education while using an online learning environment providing online lecture recordings. The aim of this work is to gain insight into how students actually regulate their online learning experience, in order to derivate possible pedagogic interventions to enhance students' learning experience and to assist them in a more strategic application of useful learning strategies.

The remainder of this paper is divided into three main sections: First, a brief overview of the theoretical background and existing work on SRL strategies in online learning environment is given. Second, the interview study's design and methodology are presented, together with main findings from the data analysis. Finally, the results are discussed, providing an outlook on future research opportunities.

\section{SRL Strategies in Online Learning Environments}

Self-regulated learning is understood as "an individual's deliberate and strategic planning, enactment, reflection, and adaptation when engaged in any task in which learning occurs" [3]. Thus, it encompasses active processes students undertake to advance their learning [4]. SRL theory has a strong foundation in self-determination theory [5] and social cognitive theory [6, 7].

A recent investigation of SRL strategies and their influence on goal achievement in MOOCs observed goal-setting and strategic planning to have a particularly positive influence on course goal achievement, while the other four strategies analyzed (selfevaluation, task strategy, elaboration, and help-seeking) appeared to provide limited to no support for learners [8]. Surprisingly, help-seeking appeared to have a negative impact on course goal achievement, on closer look, however, this effect proved to be particularly pronounced in learners with less SRL skills, particularly students, while learners with higher educational degrees and more developed SRL skills could profit from relying on others for assistance.

In contrast, in a meta-analysis of recent studies on SRL strategies and their influence on academic achievement in online learning environments [2] peer learning was found to have the strongest positive effect on academic achievement, followed by time management and effort regulation. However, the 95\% confidence interval for peer learning was extremely wide with a range from high effect down to slight negative effect on learners' achievement, which suggests additional factors may moderate the positive influence peer assistance can have on learners' success. The other eight SRL strategies included in this meta-analysis (metacognition, time management, effort regulation, peer learning, elaboration, rehearsal, help seeking, and critical thinking) were less effective, with elaboration being nearly completely ineffective, and rehearsal showing a slight negative effect. 
These findings were at least partially reproduced in a recent comparison of online and blended learning environments concerning use and effects of SRL strategies on academic achievement [9]: The findings show time management and effort regulation strategies to be the only significant positive influences on academic success of online learners, while blended learners appear to profit from more strategies such as elaboration and metacognition techniques, as well as critical thinking.

To summarize, recent research shows a positive influence of SRL strategies on students' academic achievement. Especially organizational strategies such as goal setting, time management, effort regulation and strategic planning appear to influence the learning experience in a positive way. The positive effect of peer-assisted learning appears to be quite volatile and likely depends on external moderating factors.

For researchers and university instructors, one of the main open questions is how they can adapt their curricula and create a learning environment encouraging and scaffolding students' effective use of SRL strategies in order for them to achieve academic success. The following study aims to provide insight into the current state of university students' SRL behavior by investigating how they apply which strategies in their online learning.

\section{Interview Study}

\subsection{Design and Methodology}

To gain a more detailed and qualitative view of students' motivational backgrounds and use of SRL strategies in the context of online lecture videos, a series of guided, problem-centered interviews $[10,11]$ was conducted with thirteen undergraduate students at Ludwig-Maximilians-Universität Munich, Germany (LMU Munich). This particular method of data gathering has the advantage of being open enough to allow for possibly new revelations from interview subjects' responses, while still following a thematic guideline which focuses the contents of the interview on a certain subject, in this case the interviewee's learning strategies while using online lecture videos from a web site provided by their university.

The central tool for problem-centered interviews is the interview guide, which is supposed to guide the interview conversation, presenting the interviewer with a fallback mechanism in case the open conversation becomes stalled or runs the risk of going off-topic. The guide for this study was prepared by participants of an advanced seminar in the learning sciences as part of their course assignment.

The contents of the interviews were to be focused on students' learning strategies in the context of their use of online lecture videos. The main structuring points were thus: personal learning goals (long and short term), overall planning strategy, task-related planning and regulation strategy, time management, elaboration techniques, selfevaluation strategies, and peer learning and academic help-seeking. These strategies are combined derivates of SRL strategies found to be present in higher education contexts according to previous research $[8,9]$.

Interview subjects $(\mathrm{N}=13)$ were enrolled in undergraduate study programs in the learning sciences or teacher education and had to be at least in their second year of 
studies, to ensure at least basic experience in self-regulated learning in general and the online learning environment mentioned below. Subjects were recruited and interviewed by the same aforementioned seminar participants in advanced learning sciences.

Each interview session lasted between 30 and $60 \mathrm{~min}$. The interviews were recorded digitally using personal recording devices and subsequently transcribed and anonymized. These transcripts were then analyzed using MAXQDA 2018 for Mac for coding and result aggregation.

\subsection{The Learning Environment}

At LMU Munich, several undergraduate lectures in the educational sciences and in teacher education programs are regularly recorded and made available online for students to work with - either as a replacement for classroom attendance during lecture times, or as supplementary material, e.g. to review certain subjects during exam preparations [12]. Apart from providing a general service to students, in some cases instructors make a full lecture course available exclusively online, e.g. when they are on sabbatical and still want to or are required to offer the course, and sometimes instructors use pre-recorded video sessions to experiment with modern teaching concepts such as flipped classrooms.

These online video lectures are made available via a public web site of the university, with some lectures being openly accessible, some restricted to students of the university or certain departments, according to instructors' wishes. Online lecture recordings usually include audio and video from the instructor and synchronized presentation slides. Students who log into the site with their university credentials have access to some more functionality, namely a personalized viewing history and bookmarks for their recently accessed lectures, as well as a more interactive user interface with an enhanced video player, allowing them to add time- and location-sensitive annotations to the online presentation slides, either for their private use, or as means of interaction amongst themselves and with instructors.

\subsection{Main Findings}

This section presents the key results found by analyzing the anonymized interview transcripts.

Goal Setting. In terms of goal-setting and overall motivation, most subjects speak about wanting to graduate successfully overall, only two students state they aim for high marks as well. Having a bachelor's degree is understood as a requirement for later success on the job market, and high marks are perceived as enhancing factor for job success, guaranteeing higher job positions and/or higher wages. Aside from the longerterm goals, passing the exams and graduating within the prescribed time seems to be a prevailing sentiment - the latter most pronounced in those interview subjects with previous educational experience, be it from an earlier apprenticeship or an earlier university degree.

Strategic Planning. About half of the interview subjects do not strategically plan and distribute their learning activities during the course of a semester, focusing their main 
effort on immediate exam preparations, usually near the end of the semester. Those students who do apply strategic planning to their learning experience create study plans - mostly weekly, some per semester - and try to stick to them. Only one student reports regularly working with study groups.

Task Strategy \& Effort Regulation. With respect to short term planning, only very few students report actually planning their learning task and setting up their learning environments. Actions are usually limited to choosing a place to work - the choice apparently being only between the university library and home - making sure the environment is relatively quiet and putting the phone out of immediate reach. For two students, this last point does not appear to be strong either, as one states they watch lectures while doing housework, and another admits playing video games on their phone while having the lecture video running on their laptop.

Time Management. Two students report watching the online lectures in (self-)predefined blocks of 30-45 min, two students usually watch the full $90 \mathrm{~min}$ of a regular lecture session, with breaks between sessions. The other students either do not reserve explicit time frames for watching the online videos, or they have no fixed schedule, watching the recordings when it suits them or when the exam date sets limits to procrastination.

Elaboration \& Rehearsal. Almost all interview subjects rely on personal notes, which are usually consulted at a later time, e.g. before the next lecture session, but more frequently during immediate exam preparation. The actual implementation of this strategy varies between individuals, as some take initial notes with the presentation slides as base material before viewing the online video, adding more context to these notes during video playback, while others take notes during their watching the lecture recording, either with and/or on printed or digital presentation slides or on a separate notepad. One student reported not taking notes at all, relying solely on the video recording.

Self-evaluation. Self-evaluation strategies are only mentioned in few interview subjects' responses, and usually they consist of testing their knowledge against exam questions from earlier years.

Peer Learning \& Help Seeking. Only four interview subjects talk about relying on peers to assist their learning experience. One student participates in regular study group sessions at the university library (mentioned above), the other three falling back to peer support mainly on specific topics or to check if they missed important parts during their solitary study sessions. Academic help seeking (i.e. turning to instructors or mentors at university) was not mentioned during any of the interviews and did not appear to be a viable option for the students. 


\section{Conclusion}

\subsection{Discussion}

The findings presented in the previous section paint a mixed picture of university students' knowledge and use of SRL strategies to achieve academic success.

The strategies employed most fall into the rehearsal and elaboration category, as well as time management. The latter might seem positive at first glance, since previous research shows time management to be a key supporting strategy for academic success in online learning contexts [2,9]. However, more than half of the subjects focus most of their time and effort on reviewing video recordings and their notes during their acute exam preparation. Focusing cognitive energy on elaboration and rehearsal may seem like an appropriate strategy to reach the goal of passing the next exam, however, these strategies have been shown to have no significant influence on academic success [2, 8]. Considering a regular semester at LMU Munich consists of 13-15 weeks of regular classes, followed by what is commonly called the "exam phase" of 2-4 weeks where most lecture exams take place, and the lecture-free time, which is usually reserved for writing term papers, internships to gain job experience, and vacation time, the usually allocated period of time of 2-6 weeks of immediate exam preparation seems rather short for long-term academic success. In contrast, students' stated goals in general appear to be mostly long-term, i.e. looking to graduate or at least pass all the exams in a timely fashion. While these long-term goals may help keep the overall focus on their studies, the lack of smaller, more short-term learning goals may explain the pattern described by most of the interviewed students, i.e. focusing time and energy on the time frame shortly before the exam at the end of semester.

Another striking observation is the very limited or non-existent level of task-related strategy combined with little effort regulation regarding students' personal learning space and environment. Though effort regulation is a key effective SRL strategy with respect to academic success [2,9], little effort is put into actually using this strategy for a more effective learning experience. It is highly doubtful that the behavioral manifestation displayed in this study's interviews can yield long-term positive results, especially in cases such as the two students deciding not only to not exclude possible distractions from their work space, but rather decide to undertake additional, external activities, e.g. doing housework or playing games on their phones - most notably since off-task multi-tasking has been shown to be detrimental to learners' success [13].

The lack of reliance on peer support or academic help via instructors or mentors at university may be surprising, but is actually in line with cited research, e.g. Broadbent's study comparing blended and online learners' SRL strategies [9]. As posited by Broadbent, students may not necessarily know all possible forms of peer learning, which may lead to the underrepresentation observed here as well. If students do not view non-obvious forms of peer assistance as such, they will not readily report this type of SRL strategy in an open question interview. Other factors at play may be individual differences such as previous learning experience, and low-barrier support for help seeking - be it from peers or instructors. Kizilcec et al. [8] note course participants with higher educational background are less likely to seek help and attribute this to their 
higher degree of self-regulation and stronger confidence in their own capabilities, while students were more likely to seek help, but often did not act on this, at least not observably in course forums or chat rooms.

\subsection{Implications for Research and Educational Practice}

Despite the obvious limitations of a qualitative interview analysis with respect to reliability and external validity, this study provides additional insight into university students' use of and experience in SRL strategies. The limited and suboptimal use of SRL strategies even by students of the learning sciences who are not new to higher educational contexts (both in theory through their course programs as well as in practice by being in their second or higher year of studies at university) leads to questions about the underlying reasons for students' problems in dealing with online learning requiring high SRL skills, and how instructors can provide a scaffolding environment for students to acquire and use the necessary skills to successfully reach the goals set by curricula and themselves.

From a research perspective, more in-depth analyses are needed in order to present instructors with detailed teaching interventions they can implement to enhance their students' learning experience. Broadbent [9] suggests the use of measuring tools more specialized to online learning environments such as the Online Self-regulated Learning Questionnaire (OSLQ) [14] or the Online Help Seeking Questionnaire (OHSQ) [15] for quantitative analysis, which might deliver more accurate data on help seeking and peer learning behavior in online learning contexts. One major implication for future research is the need to pursue a mixed-method approach, combining self-reported with objective data from more than one source, e.g. by adding the online learning system's log, artifacts from user forums in online learning environments, etc. [2, 3, 16].

Following the results of this study alone, a few recommendations can be made for instructors to start from. To counter the lack of effective time management and effort regulation strategies, specific training courses may be needed. These should probably be implemented and offered at an early stage in study programs, preferably during the first two semesters, in order to lay the foundation for successful transference into advanced studies. Such courses might be led by advanced students of the same subject, providing peer support, coaching younger students on how to effectively integrate SRL strategies when working with online lecture videos. Ideally, such an arrangement could also be leveraged to create a sense of community [17], leading to the building and integration of online communities of practice [18].

University students today seem to fail at effectively self-regulating their online learning experience. They may pass exams and graduate with bachelor's and higher degrees, but questions may be raised as to whether they are actually gaining the knowledge they should be able to reach, and how instructors can improve this situation by providing more scaffolds in learning environments in general. 


\section{References}

1. Hartley, K., Bendixen, L.D.: Educational research in the internet age: examining the role of individual characteristics. Educ. Res. 30, 22-26 (2001)

2. Broadbent, J., Poon, W.L.: Self-regulated learning strategies \& academic achievement in online higher education learning environments: a systematic review. Internet High. Educ. 27, $1-13$ (2015)

3. Järvelä, S., Hadwin, A., Malmberg, J., Miller, M.: Contemporary perspectives of regulated learning in collaboration. In: Fischer, F., Hmelo-Silver, C.E., Goldman, S.R., Reimann, P. (eds.) International Handbook of the Learning Sciences, pp. 127-136. Routledge, New York (2018)

4. Zimmerman, B.J.: Investigating self-regulation and motivation: historical background, methodological developments, and future prospects. Am. Educ. Res. J. 45, 166-183 (2008)

5. Deci, E.L., Ryan, R.M.: Self-determination theory. In: van Lange, P.A.M., Kruglanski, A.W., Higgins, E.T. (eds.) Handbook of Theories of Social Psychology, vol. 1, pp. 416-437. SAGE Publications Ltd., London (2012)

6. Bandura, A.: Self-efficacy: toward a unifying theory of behavioral change. Psychol. Rev. 84, 191-215 (1977)

7. Bandura, A.: Social cognitive theory. In: van Lange, P.A.M., Kruglanski, A.W., Higgins, E.T. (eds.) Handbook of Theories of Social Psychology, vol. 1, pp. 349-374. SAGE Publishing Ltd., London (2012)

8. Kizilcec, R.F., Pérez-Sanagustín, M., Maldonado, J.J.: Self-regulated learning strategies predict learner behavior and goal attainment in Massive Open Online Courses. Comput. Educ. 104, 18-33 (2017)

9. Broadbent, J.: Comparing online and blended learner's self-regulated learning strategies and academic performance. Internet High. Educ. 33, 24-32 (2017)

10. Witzel, A.: The Problem-centered Interview. Forum Qualitative Sozialforschung/Forum: Qualitative Social Research, vol 1, No 1 (2000): Qualitative Research: National, Disciplinary, Methodical and Empirical Examples (2000)

11. Witzel, A., Reiter, H.: The Problem-Centred Interview: Principles and Practice. Sage Publications, London (2012)

12. Pedrotti, M., Aulinger, J., Nistor, N.: Vorlesungsaufzeichnungen zur Unterstützung der Lehramtsausbildung an der LMU München. Zeitschrift für Hochschulentwicklung 9, 74-84 (2014)

13. Wood, E., Zivcakova, L., Gentile, P., Archer, K., De Pasquale, D., Nosko, A.: Examining the impact of off-task multi-tasking with technology on real-time classroom learning. Comput. Educ. 58, 365-374 (2012)

14. Barnard, L., Lan, W.Y., To, Y.M., Paton, V.O., Lai, S.-L.: Measuring self-regulation in online and blended learning environments. Internet High. Educ. 12, 1-6 (2009)

15. Cheng, K.-H., Tsai, C.-C.: An investigation of Taiwan University students' perceptions of online academic help seeking, and their web-based learning self-efficacy. Internet High. Educ. 14, 150-157 (2011)

16. Panadero, E.: A review of self-regulated learning: six models and four directions for research. Front. Psychol. 8, 422 (2017) 
17. Nistor, N., Daxecker, I., Stanciu, D., Diekamp, O.: Sense of community in academic communities of practice: predictors and effects. High. Educ. Int. J. High. Educ. Educ. Plann. 69, 257-273 (2015)

18. Nistor, N., Schworm, S., Werner, M.: Online help-seeking in communities of practice: modeling the acceptance of conceptual artifacts. Comput. Educ. 59, 774-784 (2012)

Open Access This chapter is licensed under the terms of the Creative Commons Attribution 4.0 International License (http://creativecommons.org/licenses/by/4.0/), which permits use, sharing, adaptation, distribution and reproduction in any medium or format, as long as you give appropriate credit to the original author(s) and the source, provide a link to the Creative Commons license and indicate if changes were made.

The images or other third party material in this chapter are included in the chapter's Creative Commons license, unless indicated otherwise in a credit line to the material. If material is not included in the chapter's Creative Commons license and your intended use is not permitted by statutory regulation or exceeds the permitted use, you will need to obtain permission directly from the copyright holder. 